VALVE DISEASE

AND STRESS ECHO-

CARDIOGRAPHY

\title{
When to use stress echocardio- graphy in the evaluation of patients with valvular heart disease
}

Vuyisile T. Nkomo, Patricia A. Pellikka,

Maurice Enriquez-Sarano and Robert B. McCully

Mayo Clinic, Rochester, Minnesota, USA

Address for correspondence:

DrVuyisile T. Nkomo

Mayo Clinic

Division of Cardiovascular Diseases and Internal Medicine

Rochester

Minnesota 55905

USA

Email:

nkomo.vuyisile@mayo.edu

\section{ABSTRACT}

Stress testing and stress echocardiography are firmly established diagnostic tests in the evaluation of patients with suspected or known coronary artery disease, but less established in the evaluation of patients with valvular heart disease. However, there is emerging data supporting the incremental benefit of stress testing and stress echocardiography in patients with known valvular heart disease. Particular applications include hemodynamic assessment of valve function and pulmonary response during exerciseinduced or chemically-induced stress to correlate with the patient's exertional symptoms. In addition, stress testing affords the opportunity for functional assessment of ventricular systolic function for prognostication and planning for surgery. SAHeart 2010; 7:94-105

\section{INTRODUCTION}

Valvular heart diseases are a major public health problem worldwide. ${ }^{(1,2)}$ Rheumatic heart disease is the leading cause of valve disease in economically developing countries ${ }^{(3-5)}$ and degenerative or aging-related valve diseases predominate in economically developed countries. ${ }^{(2,6)}$ The majority of valve diseases are chronic and left-sided, affecting the mitral and aortic valves. The valves become stenosed or regurgitant. The development of symptoms (exertional dyspnoea, fatigue, angina, presyncope, syncope) typically occurs when the valve disease is severe and the symptoms are usually brought on by exertion. However, symptoms may be imperceptible because they can develop gradually and may not be reported by the patient, or the patient may be too sedentary to develop symptoms. Additionally, some patients with severe valve disease remain asymptomatic despite being active. Symptoms related to valve disease lead to decreased exercise tolerance and impaired quality of life. They may also indicate impending heart failure and death if the valve lesion is not corrected. The mainstay of treatment of severe valve disease is valvuloplasty (for mitral stenosis in suitable candidates) or surgery (valve replacement or repair).
Valve diseases come to attention because a murmur is detected on physical examination, but 2-D and Doppler echocardiography is superior to physical examination for detecting valve disease and should be utilised in the clinical evaluation of patients who have cardiac symptoms even in the absence of an audible or "loud" murmur on physical examination. Echocardiography is the single most useful test for determining the etiology and severity of valve disease and is the test of choice for guiding the management of patients with valve disease. Hemodynamic consequences of cardiac chamber remodelling with changes in ventricular and atrial size and function and/or pulmonary pressures commensurate with severe stenosis or regurgitation can be assessed by echocardiography and used for risk stratification and timing of therapeutic intervention. In addition, unsuspected coexistent heart diseases may be diagnosed during evaluation of valve disease.

In symptomatic patients, a resting echocardiogram that shows anatomically severe valve disease and associated hemodynamic abnormalities usually provides sufficient information to refer the patient to surgery. ${ }^{(7,8)}$ Stress testing in those patients is not indicated unless there is a need to assess for hibernating myocardium 
or left ventricular contractile reserve when planning for surgery. Stress testing and stress echocardiography are useful and indicated for patients who report exertional symptoms, but who only appear to have mild to moderate valve disease at rest that would not be expected to cause symptoms. Stress testing is also useful for assessing patients who are sedentary and who do not report symptoms despite having severe valve disease.

The discussion below will focus on left-sided native valve diseases and clinical situations where stress testing and stress echocardiography are useful for decision-making.

\section{MITRAL STENOSIS}

Mitral stenosis is caused by structural abnormalities of the mitral valve apparatus that lead to improper opening of the valve and subsequent obstruction to left ventricular filling during diastole. ${ }^{(7,9,10)}$ The predominant cause of mitral stenosis is inflammation of the mitral valve from rheumatic fever which leads to valvular and/or subvalvular thickening and calcification and commissural fusion. As the valve narrows the left atrial pressure increases to continue driving blood into the left ventricle; a measurable pressure gradient develops across the valve during diastole. ${ }^{(7,11)}$ The increased left atrial pressure is reflected back into the pulmonary circulation and may lead to pulmonary congestion and pulmonary venous and even pulmonary arterial hypertension. The associated symptoms are dyspnoea and fatigue or pulmonary oedema. ${ }^{(1,12)}$ The normal mitral valve area is $4-6 \mathrm{~cm}^{2}$ and symptoms usually do not develop until the valve area is less than $2.5 \mathrm{~cm}^{2} ;(7,13)$ a valve area $>1.5 \mathrm{~cm}^{2}$ usually does not produce symptoms at rest.(14) Development of symptoms or pulmonary hypertension in mitral stenosis is associated with a poor outcome if left untreated. (12)

TABLE I: Grading of severity of mitral valve stenosis $\left.{ }^{7}\right)$

\begin{tabular}{l|c|c|c|}
\hline & Valve area & Mean gradient & $\begin{array}{c}\text { Pulmonary artery } \\
\text { systolic pressure }\end{array}$ \\
\hline Mild & $>1.5 \mathrm{~cm}^{2}$ & $<5 \mathrm{mmHg}$ & $<30 \mathrm{mmHg}$ \\
\hline Moderate & $1-1.5 \mathrm{~cm}^{2}$ & $5-10 \mathrm{mmHg}$ & $30-50 \mathrm{mmHg}$ \\
\hline Severe & $<1 \mathrm{~cm}^{2}$ & $>10 \mathrm{mmHg}$ & $>50 \mathrm{mmHg}$ \\
\hline
\end{tabular}

The pressure gradient across the mitral valve is a function of the square of the flow across the valve and is dependent on the diastolic filling period. ${ }^{(7,11)}$ Therefore, symptoms in mitral stenosis are usually precipitated by an increase in flow or heart rate and the degree of valve stenosis at rest may not reflect the true severity of obstruction with exercise. ${ }^{(7,14)}$

Guidelines for management of mitral stenosis are based on a point scale comprised of the mitral valve area, transmitral mean gradient and pulmonary artery systolic pressure (Table I). ${ }^{(7)}$ Severe mitral stenosis is defined as a mitral valve area $<1 \mathrm{~cm}^{2}$, a transmitral mean pressure gradient $>10 \mathrm{mmHg}$ or pulmonary artery systolic pressure $>50 \mathrm{mmHg}$. Patients with severe mitral stenosis benefit from mitral valvuloplasty or surgery. ${ }^{(7)}$

Mitral valve area (MVA) is determined by the pressure half-time (PHT) or continuity equation methods. (15-19) $\mathrm{PHT}$ refers to the time it takes for the transmitral gradient to reach half of the initial peak gradient and is determined by the slope of the continuous wave Doppler signal across the stenotic mitral valve. The initial peak gradient is higher and the PHT longer with worsening mitral stenosis. Mitral valve area is calculated by the formula:

$$
\text { MVA }=220 / \mathrm{PHT}
$$

The PHT can be shortened in the presence of severe mitral stenosis if there is underlying decreased left atrial compliance since the high left atrial pressure may lead to more rapid equalisation of left atrial and left ventricular pressures during diastole. ${ }^{(20)}$ Conditions that cause a rapid rise in left ventricular pressure during diastole such as the presence of decreased left ventricular compliance or severe aortic regurgitation may also lead to a shortened PHT and overestimation of mitral valve area (that is, underestimation of severity of mitral stenosis). ${ }^{(19)}$ Calculation of the mitral valve area using the continuity equation (Figure I) requires measurements of the forward stroke volume from the left ventricular outflow tract (LVOT) diameter (D), LVOT time velocity integral (TVI), and mitral valve TVI and using the following equation:

$$
M V A=\left(L V O T D^{2} \times 0.785 \times T_{L_{L V O T}}\right) / T V I_{M V}
$$

However, this equation should not be used in the presence of significant aortic regurgitation because it will result in underestimation of the severity of mitral stenosis. ${ }^{(21)}$ Furthermore, severe 


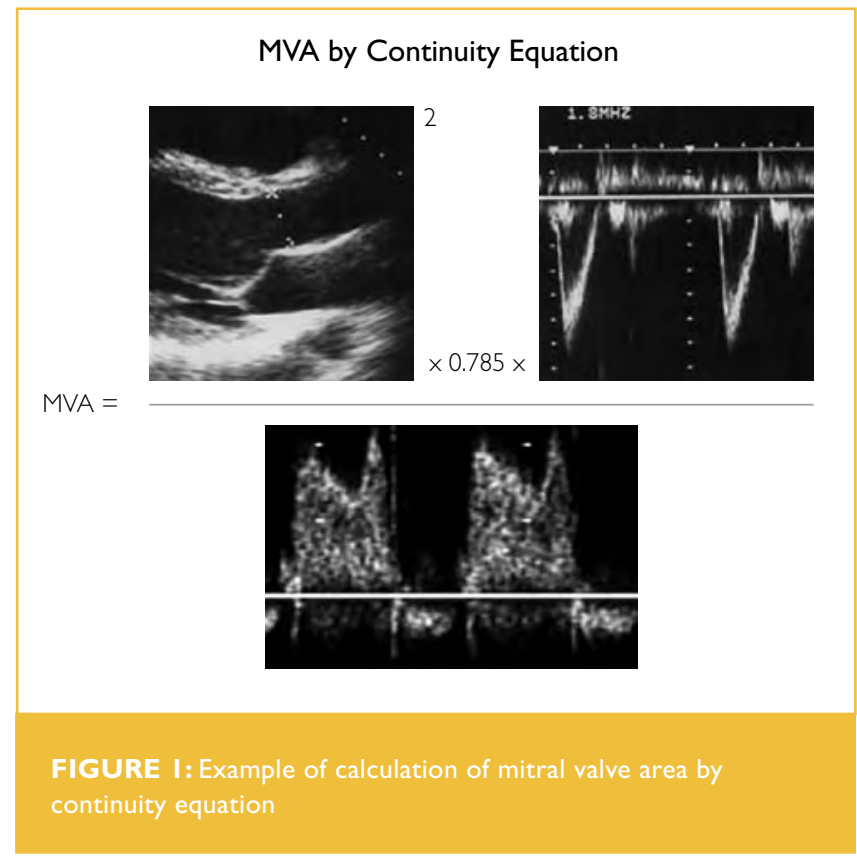

mitral regurgitation can cause overestimation of the severity of mitral valve stenosis if this equation is applied. ${ }^{(19)}$ The mitral valve area can also be determined directly by planimetry of the mitral valve area at the tips of the mitral valve in the parasternal shortaxis view. The mean transmitral gradient is determined by tracing the continuous wave Doppler signal across the stenotic mitral valve. If significant mitral regurgitation is present, the increased flow results in a higher transmitral gradient. Thus, a comprehensive evaluation of mitral stenosis should include assessment of the severity of mitral regurgitation.

Pulmonary artery systolic pressure (PASP) is estimated from the peak velocity of the tricuspid regurgitation (TR) continuous wave signal and right atrial pressure (RAP) using the modified Bernoulli equation:

$$
P A S P=4 \times T R^{2}+R A P
$$

(RAP is estimated from the size of the inferior vena cava. If the diameter of the inferior vena cava decreases by $50 \%$ or more during inspiration, RAP is usually $<10 \mathrm{mmHg}$, and if the diameter decreases less than $50 \%$, RAP is usually $>10 \mathrm{mmHg}$ ). ${ }^{(22)}$

\section{Stress echocardiography for mitral valve stenosis}

A symptomatic patient whose resting echocardiogram shows severe mitral stenosis is considered to have symptomatic severe mitral valve stenosis and stress echocardiography is not indicated. ${ }^{(23)}$
Patients who appear to have mild to moderate mitral stenosis at rest but who report symptoms of dyspnoea or fatigue may have another cause for their symptoms (such as lung disease or deconditioning), or may have hemodynamically severe mitral stenosis during exercise, since 2-D and Doppler hemodynamic determination of mild to moderate mitral stenosis at rest may not reflect the hemodynamic severity of the stenosis with exercise. Symptom-limited stress echocardiography (exercise or dobutamine) is useful in patients with mild to moderate mitral stenosis at rest to assess the transmitral mean gradient and pulmonary pressures at peak stress in order to establish a link between the patient's exertional symptoms and stress-induced hemodynamic abnormalities. ${ }^{(24-30)}$

During exercise, a rise in the transmitral mean diastolic gradient to $>15 \mathrm{mmHg}$ along with a rise in pulmonary artery systolic pressure to $>60 \mathrm{mmHg}$ associated with symptoms identifies a group of patients who have hemodynamically severe mitral stenosis and who would benefit from mitral balloon valvuloplasty or mitral valve surgery. ${ }^{(7,25,31,32)}$ Some of these patients, however, may respond to more aggressive medical therapy, which is aimed at blunting the heart rate response to exercise. Therefore, exercise stress testing may be used to tailor medical therapy. A rise in pulmonary artery systolic pressure with exercise without a significant rise in the mean diastolic gradient suggests pulmonary disease. ${ }^{(33)}$

Supine bicycle exercise is preferable to treadmill exercise because hemodynamic data can be obtained during each stage of exercise. ${ }^{(28,31,33)}$ The development of a mean gradient $\geq 18 \mathrm{mmHg}$ with dobutamine stress in patients with non-severe mitral stenosis at rest identifies a group at high risk of developing subsequent dyspnoea or pulmonary oedema requiring hospitalisation, subsequent arrhythmias, or requiring mitral valve interventions. ${ }^{\left({ }^{(4)}\right)}$ Table 2 outlines variables that should be obtained at rest and during stress for clinical decision making. Additionally, colour flow imaging of the mitral valve is recommended because the severity of regurgitation can increase with exercise in patients with mixed mitral valve disease. The mitral valve area is not expected to change much from rest to stress, although it can be calculated accurately with the continuity equation or by planimetry. ${ }^{(30,35,36)}$ The PHT during stress may be inaccurate for estimating valve area. ${ }^{(25,28,37-39)}$ Exercise echo- 
cardiography can also be used to assess haemodynamics after mitral valve balloon valvuloplasty. ${ }^{(40)}$

\section{MITRAL REGURGITATION}

Unlike mitral valve stenosis, which is almost always caused by rheumatic carditis, the predominant causes of mitral valve regurgitation differ between developing and developed countries. Rheumatic carditis remains the major cause of mitral regurgitation in developing countries and is the predominant cause of heart failure in children and young adults with active rheumatic carditis. ${ }^{(41)}$ In developed countries, mitral regurgitation is most commonly related to degenerative mitral valve disease often associated with aging.(2) Another important cause of mitral regurgitation is functional mitral regurgitation related to ischaemic or non-ischaemic cardiomyopathy, but the relative global distribution of this etiology of mitral regurgitation is unknown.

Severity of mitral valve regurgitation is determined by a variety of methods including qualitative, semi-quantitative, and quantitative measurements (Table 3). ${ }^{(42)}$ The reader is referred to the American Society of Echocardiography Recommendations for evaluation of the severity of native valvular regurgitation with two-dimensional and Doppler echocardiography ${ }^{(42)}$ for complete details of the criteria including their utility, advantages, and limitations. In asymptomatic patients, quantitative grading of mitral regurgitation is a powerful predictor of subsequent atrial fibrillation, heart failure, or death where the effective regurgitant orifice (ERO) surpasses all other qualitative or quantitative measurements as a prognosticator. ${ }^{(43)}$

TABLE 2: Key data to be acquired at rest and during stress during assessment of severity of mitral valve stenosis

\begin{tabular}{|lcc|}
\hline & Rest & Stress \\
\hline Blood pressure & $\times$ & $\times$ \\
\hline Heart rate & $\times$ & $\times$ \\
\hline MVA & $\times$ & \\
\hline Mean gradient & $\times$ & $\times$ \\
\hline TR velocity & $\times$ & $\times$ \\
\hline Symptoms & $\times$ & $\times$ \\
\hline Exercise duration & & $\times$ \\
\hline
\end{tabular}

Stress echocardiography in mitral valve regurgitation

\section{Rheumatic mitral regurgitation}

Severe mitral regurgitation from rheumatic carditis is typically associated with symptoms of dyspnoea, fatigue, or heart failure. Surgery is indicated for symptomatic patients with severe rheumatic mitral regurgitation and there is no role for stress testing.

Patients who report symptoms, but who appear to have mild to moderate mitral regurgitation at rest should undergo symptomlimited exercise echocardiography to determine whether the mitral regurgitation severity increases with exercise and if pulmonary hypertension develops (pulmonary artery systolic pressure $>60 \mathrm{mmHg}$. ${ }^{(7,33)}$ An increase in the severity of mitral regurgitation correlates well with elevation of pulmonary artery systolic pressure. ${ }^{(44,45)}$

\section{TABLE 3: Qualitative and quantitative parameters for grading mitral regurgitation severity (with permission from the American Society of Echocardiography) ${ }^{(42)}$}

\begin{tabular}{|c|c|c|c|}
\hline & Mild & Moderate & Severe \\
\hline \multicolumn{4}{|l|}{ Structural parameters } \\
\hline LA size & Normal & Normal or dilated & Usually dilated \\
\hline LV size & Normal & Normal or dilated & Usually dilated \\
\hline $\begin{array}{l}\text { Mitral leaflets or } \\
\text { supporting structures }\end{array}$ & $\begin{array}{l}\text { Normal or } \\
\text { abnormal }\end{array}$ & $\begin{array}{l}\text { Normal or } \\
\text { abnormal }\end{array}$ & $\begin{array}{l}\text { Abnormal/flail } \\
\text { leaflet/Ruptured } \\
\text { papillary muscle }\end{array}$ \\
\hline \multicolumn{4}{|l|}{ Doppler parameters } \\
\hline $\begin{array}{l}\text { Colour flow jet } \\
\text { (at Nyquist limit of } \\
50-60 \mathrm{~cm} / \mathrm{s} \text { ) }\end{array}$ & $\begin{array}{l}\text { Small central jet } \\
\text { (usually }<4 \mathrm{~cm}^{2} \\
\text { or }<20 \% \text { of } \\
\text { LA area) }\end{array}$ & Variable & $\begin{array}{l}\text { Large central jet } \\
\text { (usually }>10 \mathrm{~cm}^{2} \\
\text { or }>40 \% \text { of } \\
\text { LA area) or } \\
\text { variable size wall- } \\
\text { impinging jet } \\
\text { swirling in LA }\end{array}$ \\
\hline Mitral inflow-PW & A-wave dominant* & Variable & $\begin{array}{l}\text { E-wave dominant* } \\
\text { (E usually }>1.2 \mathrm{~m} / \mathrm{s} \text { ) }\end{array}$ \\
\hline Jet density-CW & Incomplete or faint & Dense & Dense \\
\hline Jet contour=CW & Parabolic & Usually parabolic & $\begin{array}{l}\text { Early peaking- } \\
\text { triangular }\end{array}$ \\
\hline Pulmonary vein flow & Systolic dominance & $\begin{array}{l}\text { Systolic blunting } \\
\text { may be present }\end{array}$ & $\begin{array}{l}\text { Systolic reversal } \\
\text { may be present }\end{array}$ \\
\hline \multicolumn{4}{|c|}{ Quantitative parameters } \\
\hline VC width $(\mathrm{cm})$ & $<0.3$ & $0.3-0.69$ & $\geq 0.7$ \\
\hline RVol (ml/beat) & $<30$ & $30-59$ & $\geq 60$ \\
\hline RF (\%) & $<30$ & $30-49$ & $\geq 50$ \\
\hline ERO $\left(\mathrm{cm}^{2}\right)$ & $<0.20$ & $0.20-0.39$ & $\geq 0.40$ \\
\hline
\end{tabular}

$C W=$ continuous-wave. $L A=$ left atrium. $E R O=$ effective regurgitant orifice.

$\mathrm{LV}=$ left ventricle. $P \mathrm{PW}=$ pulsed-wave. $R F=$ regurgitant fraction. $R$ Vol $=$ regurgitant volume.

$\mathrm{VC}=$ vena contracta.

* Usually above 50 years of age or in conditions of impaired relaxation, in the absence of mitral stenosis or other causes of elevated LA pressure. 
Supine bicycle exercise is the preferred stress testing modality because the severity of mitral regurgitation can be assessed at every stage of exercise. Qualitative and semi-quantitative measurements are easier to obtain during stress testing, but attempts should be made to assess severity of regurgitation by quantitative measurements as well. ${ }^{(42)}$

Tischler et al. reported a high incidence of exercise-induced worsening of mitral regurgitation in a group of patients with exertional dyspnoea but with only mild rheumatic mitral valve disease at rest (mild stenosis and mild regurgitation). ${ }^{(44)}$ The mechanism responsible for this increase in severity of mitral regurgitation in patients with rheumatic mitral valve disease is unclear.

\section{Degenerative mitral regurgitation}

Symptomatic patients with severe mitral regurgitation due to mitral valve prolapse or flail mitral valve leaflets should be referred to surgery. The preferred mode of surgical correction is mitral valve repair instead of mitral valve replacement. ${ }^{(7,43,46)}$ There is no indication for stress echocardiography in symptomatic patients with severe degenerative mitral regurgitation. Asymptomatic patients with overt signs of left ventricular dysfunction (left ventricular ejection fraction $\leq 60 \%$ and left ventricular end-systolic dimension $240 \mathrm{~mm}$ ) should also be referred for mitral repair: there is no role of stress testing in these patients. ${ }^{(7,8)}$

There is some debate regarding whether asymptomatic patients with severe degenerative mitral valve regurgitation and preserved left ventricular size and systolic function (not meeting and exceeding guideline cut-off values) should be referred to surgery. We favour mitral valve repair in these patients given the unavoidable consequences if left unoperated and the extremely low operative risk and excellent long term outcome of these patients. However, the surgery should be performed at centres with expertise and high success rates in mitral valve repair. ${ }^{(43,47-50)}$

Exercise testing in asymptomatic patients with severe mitral regurgitation with preserved left ventricular size and systolic function may help identify those with decreased exercise capacity due to mitral regurgitation and those with latent left ventricular dysfunction. The goal of stress testing in these patients is therefore to assess functional capacity and response of left ventricular size and systolic function to exercise. Decreased exercise capacity in asymptomatic patients (peak VO2 <84\% predicted), as assessed by cardiopulmonary exercise testing, identifies a subgroup at higher risk of developing subsequent heart failure or dying.(51) Exercise duration of $<15$ minutes on a modified Bruce protocol in asymptomatic patients with severe mitral regurgitation is associated with a much higher risk of developing left ventricular dysfunction or symptoms (average annual event risk of $23.5 \%$ versus $4.6 \%$ in those with exercise duration $\geq 15$ minutes). ${ }^{(52)}$

The inability to increase left ventricular ejection fraction $\geq 4 \%$ with exercise (that is, lack of contractile reserve) identifies patients with latent left ventricular dysfunction. ${ }^{(53-55)}$ These patients are at higher risk of developing overt left ventricular dysfunction when treated medically and at higher risk of developing postoperative heart failure. ${ }^{(54,55)}$ An exercise left-ventricular systolic volume index $>25 \mathrm{ml} / \mathrm{m}^{2}$ in minimally symptomatic patients identifies those at risk of developing postoperative heart failure. Depressed longitudinal myocardial function assessed by 2-D speckle tracking at rest and during exercise was able to identify a subgroup of patients with latent left ventricular dysfunction and predicted postoperative left ventricular dysfunction. ${ }^{(56)}$

\section{Ischaemic mitral regurgitation}

The mechanism of ischaemic mitral regurgitation is related to global and regional remodelling of the left ventricle from ischaemia or infarction. This leads to apical and posterior displacement of the papillary muscles, tenting of the mitral valve leaflets, loss of annular contraction and resultant mitral leaflet malcoaptation and regurgitation. ${ }^{(57,58)}$ Mitral regurgitation is present in up to $50 \%$ of patients following myocardial infarction ${ }^{(59)}$ and is associated with poor long term outcome even when the regurgitation is mild; the outcome is worse still when the regurgitation is moderate or more. ${ }^{(60)}$ Lesion severity in terms of the ERO and regurgitant volume that impact negatively on survival in ischaemic mitral regurgitation is much less than that of organic or degenerative mitral regurgitation (ERO $\geq 20 \mathrm{~mm}^{2}$ and regurgitant volume $\geq 30 \mathrm{ml}$ are considered severe regurgitation in ischaemic mitral regurgitation). ${ }^{(60)}$ Mitral valve surgery is recommended in patients who have severe mitral regurgitation and impaired left ventricular ejection fraction who are to undergo coronary bypass surgery. ${ }^{(8)}$ 
Mitral valve repair, however, does not appear to be superior to mitral valve replacement in patients with ischaemic mitral regurgitation. ${ }^{(61,62)}$ Surgery solely for mitral regurgitation in patients with ischaemic mitral regurgitation and impaired left ventricular systolic function does not seem to offer survival benefit, ${ }^{(63-65)}$ but may be considered for relief of symptoms in those with associated heart failure refractory to medical therapy. ${ }^{(66)}$

In some patients, mild to moderate ischaemic mitral regurgitation may become severe with exercise and these patients are at higher risk of heart failure or death. ${ }^{(67-69)}$ Ischaemic mitral regurgitation that worsens with exercise and the development of pulmonary hypertension with exercise are indeed important causes of acute pulmonary oedema in patients with left ventricular systolic dysfunction. ${ }^{(69)}$ Exercise Doppler echocardiography may therefore be helpful in elucidating the etiology of exertional symptoms or acute pulmonary oedema in patients with mild to moderate mitral regurgitation at rest. ${ }^{(69-72)}$ Worsening of the degree of mitral regurgitation during exercise is related to changes in local left ventricular remodelling and more deformation of the mitral valve apparatus leading to systolic expansion of the mitral annulus which increases the regurgitant orifice. ${ }^{(67)}$

Dobutamine stress testing in patients with ischaemic mitral regurgitation is useful for determining the presence and extent of hibernating viable myocardium ${ }^{(73)}$ since treatment of viable hibernating myocardium with revascularisation or medical therapy or cardiac resynchronisation may improve both left ventricular systolic function and mitral regurgitation. (74-77)

\section{Non-ischaemic functional mitral regurgitation}

The mechanism of mitral regurgitation in non-ischaemic dilated cardiomyopathy has also been described and is related to mitral leaflet tethering, annular expansion, and decrease in left ventricular driving forces that close the mitral valve leaflets. ${ }^{(78)}$ Mitral regurgitation is common among patients with non-ischaemic dilated cardiomyopathy and its presence impacts negatively on survival with the worst survival being in those patients with moderate to severe regurgitation. ${ }^{(79)}$ Even patients with mild degree or regurgitation have a less favourable outcome compared to those without any mitral regurgitation. ${ }^{(79)}$ As in ischaemic mitral regurgitation, a potential reason for why even mild degrees of functional mitral regurgitation are associated with poor outcome may be related to the dynamic nature of mitral regurgitation, where mitral regurgitation worsens with exercise. ${ }^{(58)}$ Yamano et al., using exercise echocardiography, demonstrated exercise-induced changes in functional mitral regurgitation in patients with non-ischaemic dilated cardiomyopathy (Figure 2) and this correlated strongly with exercise intolerance. ${ }^{(80)}$

Dobutamine changes loading conditions and usually decreases the severity of mitral regurgitation by, among other things, decreasing mitral $E R O^{(81)}$ and increasing forward left ventricular stroke volume. ${ }^{(82)}$ Dobutamine is therefore not considered a useful stress testing modality for the assessment of mitral regurgitation. Exercise, and not dobutamine, should be the stress modality when assessing whether the severity of mitral regurgitation, regardless of etiology, increases with stress.

\section{AORTIC STENOSIS}

Aortic valve stenosis may be caused by rheumatic carditis, but it is more commonly caused by an atherosclerotic and inflammatory process related to aging and cardiovascular risk factors (commonly referred to as degenerative aortic valve stenosis).(2,683-87) Criteria for severity of aortic valve stenosis are outlined in Table 4.

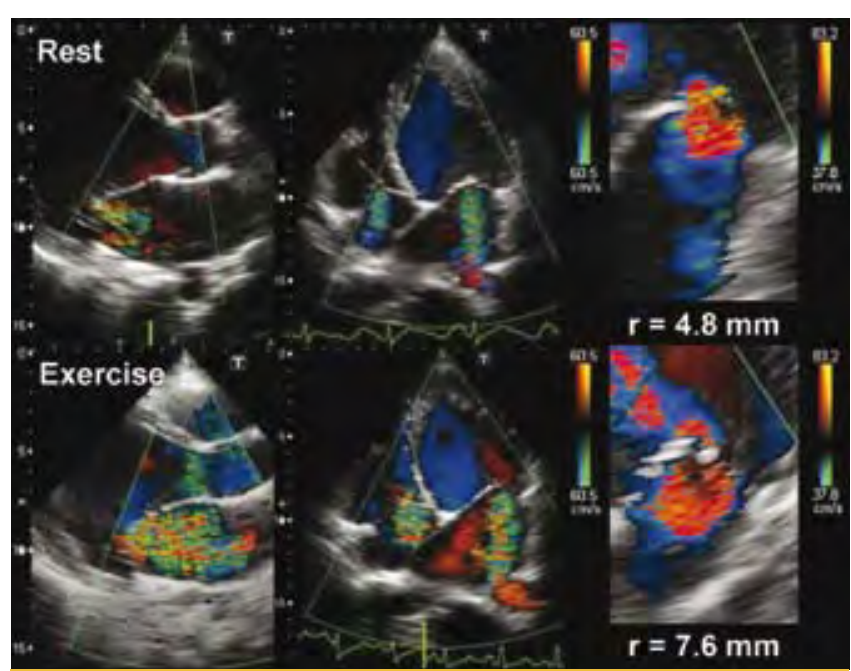

FIGURE 2: Colour Doppler echocardiograms of a patient who showed an increase in functional MR severity during exercise. The radius of the proximal isovelocity surface area $(r)$ increased from 4.8 to $7.6 \mathrm{~mm}$ (right) and the ERO from 14.2 to $29.1 \mathrm{~mm}^{2}$ (with permission)( 
TABLE 4: Grading of severity of aortic valve stenosis?

\begin{tabular}{lcccc}
\hline \hline & Valve area & $\begin{array}{c}\text { Valve area } \\
\text { index }\end{array}$ & Peak velocity & $\begin{array}{c}\text { Mean } \\
\text { gradient }\end{array}$ \\
\hline Mild & $>1.5 \mathrm{~cm}^{2}$ & & $<3 \mathrm{~m} / \mathrm{s}$ & $<25$ \\
Moderate & $1-1.5 \mathrm{~cm}^{2}$ & & $3-4 \mathrm{~m} / \mathrm{s}$ & $25-40 \mathrm{mmHg}$ \\
\hline Severe & $<1 \mathrm{~cm}^{2}$ & $<0.6 \mathrm{~cm}^{2} / \mathrm{m}^{2}$ & $>4 \mathrm{~m} / \mathrm{s}$ & $>40 \mathrm{mmHg}$ \\
\hline
\end{tabular}

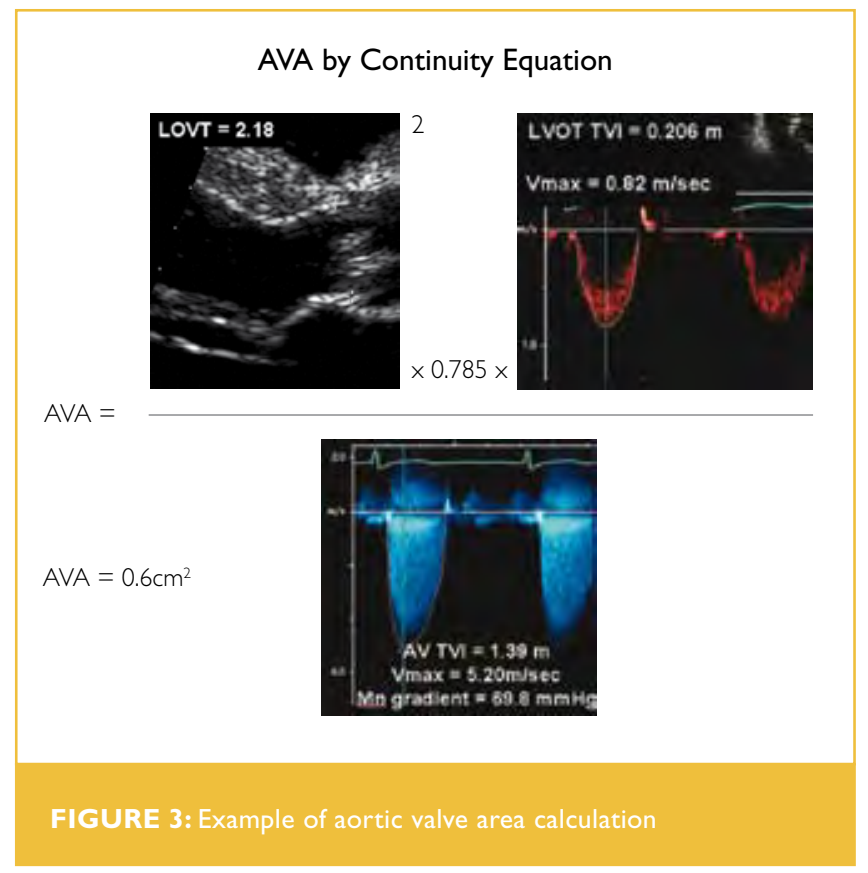

Aortic valve area (AVA) (Figure 3) is calculated from the continuity equation which requires measurements of the forward stroke volume from LVOT diameter (D), LVOT TVI, and transvalvular TVI using the following equation:

$$
A V A=\left(L V O T D^{2} \times 0.785 \times T_{V I} I_{L_{V O T}}\right) / T V I_{A V}
$$

A dimensionless index $\mathrm{TVI}_{\mathrm{LVOT}} / \mathrm{TVI}_{\mathrm{AV}}$ can also be used in cases where the diameter of the LVOT is difficult to measure. A TVI ${ }_{\text {LVOT }}$ ' $\mathrm{TVI}_{\mathrm{AV}}<0.25$ is consistent with severe aortic stenosis. (7) Symptoms related to aortic stenosis (dyspnoea, angina, and syncope being the classic triad) ${ }^{(88)}$ typically develop when the degree of aortic stenosis is severe. Prompt surgery is indicated in symptomatic severe aortic stenosis( ${ }^{(89)}$ and there is no indication for stress testing. ${ }^{(7,8)}$ Surgery is also recommended for patients with asymptomatic severe aortic stenosis with left ventricular systolic dysfunction (left ventricular ejection fraction <50\%). . 78$)$ Patients with moderate aortic stenosis should undergo aortic valve replacement if they are having open heart surgery for other reasons. ${ }^{(7,8)}$

Stress echocardiography in aortic valve stenosis

\section{Aortic stenosis with normal left ventricular systolic function}

Surgery is not generally recommended for asymptomatic patients with severe aortic valve stenosis until they develop symptoms. However, about 30\% of asymptomatic patients will develop symptoms or heart failure within two years of diagnosis. ${ }^{(90,91)}$ The risk of sudden death in asymptomatic patients with severe aortic stenosis is $<1 \%$ per year ${ }^{(92,93)}$ and some asymptomatic patients with severe aortic stenosis may develop irreversible left ventricular dysfunction, although there is no reliable data to suggest that irreversible left ventricular dysfunction develops as a result of severe aortic stenosis in the absence of symptoms. ${ }^{\left({ }^{8}\right)}$ The risk of adverse outcomes with aortic valve replacement on the other hand is about $3-5 \%$ and therefore aortic valve replacement is not recommended routinely for asymptomatic patients with severe aortic stenosis. ${ }^{(7,8)}$ Several predictors of progression of aortic stenosis and poor outcome in initially asymptomatic patients have been described and include the degree of aortic valve calcification (moderate or more), ${ }^{(94)}$ peak jet velocity across the aortic valve (peak velocity $>4.0 \mathrm{~m} / \mathrm{sec}$ ), ${ }^{(92,95)}$ and a higher rate of hemodynamic progression (increase in peak velocity across the aortic valve $>0.3 \mathrm{~m} / \mathrm{s}$ per year or decrease in aortic valve area $>0.1 \mathrm{~cm}^{2}$ per year. ${ }^{(94,95)}$

Exercise testing is useful in asymptomatic patients with severe aortic stenosis to help identify those patients at higher risk of developing symptoms and heart failure during follow up. Moreover, this may identify patients who are not truly asymptomatic Exercise treadmill testing has been shown to be safe in patients with asymptomatic severe aortic stenosis, but it has to be performed under careful and close physician supervision. ${ }^{(96-101)}$ Predictors of the development of symptoms include symptoms during exercise testing, an abnormal blood pressure response to exercise $(<20 \mathrm{mmHg}$ increase in systolic blood pressure) and the development of ST segment depression $\geq 2 \mathrm{~mm}$. ${ }^{(98,99)}$

An increase in the mean systolic Doppler gradient $\geq 18 \mathrm{mmHg}$ during exercise echocardiography was shown to have incremental prognostic value over resting echocardiography and exercise 


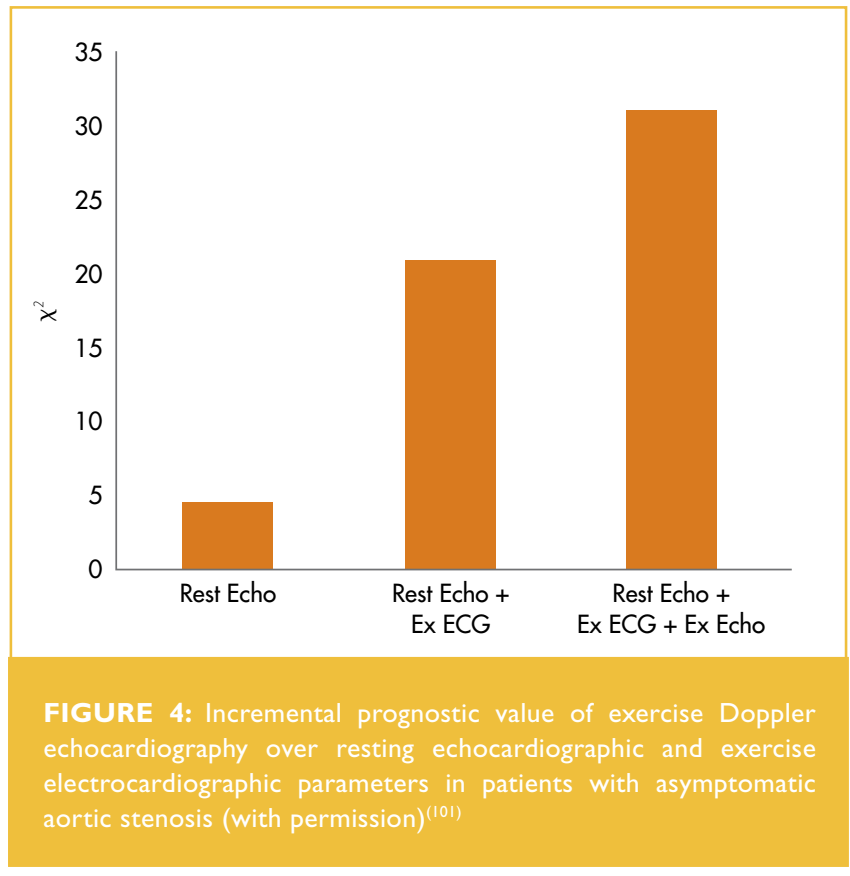

$\chi^{2}=$ chi-square. Echo $=$ echocardiography. $E x=$ exercise. $E C G=$ electrocardiogram.

treadmill data in predicting higher risk of developing symptoms, heart failure, needing aortic valve replacement, or cardiac death. ${ }^{(101)}$ (Figure 4)

\section{Aortic stenosis with reduced left ventricular systolic function}

As previously mentioned, patients who have severe aortic valve stenosis (AVA $<1 \mathrm{~cm}^{2}$ and mean gradient $>40 \mathrm{mmHg}$ ) and reduced left ventricular systolic function (LV EF <50\%) should be referred for surgery. ${ }^{(7,8)}$

However, some patients with reduced left ventricular systolic function (EF <40\%) may present with a calculated $A V A \leq 1 \mathrm{~cm}^{2}$ and a low transvalvular mean gradient $(<30 \mathrm{mmHg})$, a situation termed low gradient, low output aortic stenosis where the transvalvular gradient is discordant with the calculated valve area. ${ }^{(102)}$ In this setting, there may be fixed, severe aortic stenosis which has resulted in left ventricular systolic failure with reduced contractility and stroke volume and a low transvalvular gradient. On the other hand, both the calculated aortic valve area and transvalvular mean gradient may be low because of reduced left ventricular contractility and stroke volume from other causes and the stenosis is only mild or moderate ("relative" aortic stenosis). ${ }^{(102)}$ The two situations can be distinguished from each other by use of low to intermediate dose dobutamine echocardiography. In fixed, severe aortic stenosis an infusion of dobutamine will result in increased contractility and stroke volume and a higher mean transvalvular gradient, while the calculated aortic valve area does not change significantly. If the aortic stenosis is not severe, with the increased left ventricular contractility and stroke volume the aortic valve will open more and the valve area increases, while the mean gradient remains unchanged or only increases modestly. It is important to make the distinction between these two types of patients because those with fixed, severe aortic stenosis will benefit from aortic valve surgery, while those with relative aortic stenosis will not.(102) Therefore, dobutamine echocardiography is particularly helpful in patients with aortic stenosis with left ventricular systolic dysfunction and low transvalvular mean gradients. ${ }^{(103)}$

Since the main purpose of using dobutamine in this situation is to increase transvalvular flow and not to induce myocardial ischaemia, ${ }^{(73)}$ the incremental infusion of dobutamine stops at $20 \mathrm{ug} / \mathrm{kg} / \mathrm{min}$. Longer dobutamine infusion stages (up to 5 to 8 minutes) are recommended to avoid rapid increases in heart rate and also to allow for steady-state conditions to be reached and for careful data acquisition. ${ }^{(73)}$ Patients who have true fixed, severe aortic stenosis and left ventricular contractile reserve, defined as an increase in stroke volume $\geq 20 \%$ during dobutamine echocardiography, have a much better postoperative outcome than those without contractile reserve (stroke volume increase <20\%). (104-106) However, patients without left ventricular contractile reserve should still be considered for aortic valve replacement surgery, even though their surgical risk is higher, ${ }^{(107,108)}$ since the outlook without surgery is dismal. A significant number of patients with aortic stenosis will have coronary artery disease $^{(109)}$ and assessment for coexistent coronary artery disease in these patients should be by coronary angiography.

\section{AORTIC REGURGITATION}

Aortic regurgitation may be due to the sequelae of rheumatic carditis or may be secondary to congenital abnormalities of the valve such as bicuspid aortic valve with prolapse or quadricuspid aortic valve. Diseases of the aorta that lead to dilatation or inflammation of the aorta may also result in aortic regurgitation. Acute severe aortic regurgitation, which may occur as a result of aortic valve endocarditis or aortic dissection or blunt trauma, 
needs to be treated promptly with aortic valve surgery. On the other hand, chronic severe aortic valve regurgitation is usually well tolerated and the patient may remain asymptomatic for a long time. Surgery is recommended for patients with symptoms attributable to severe aortic regurgitation whether or not there is left ventricular systolic dysfunction. In asymptomatic patients, surgery is recommended when there are signs of left ventricular systolic dysfunction defined as left ventricular ejection fraction $\leq 50 \%$ or when there is severe left ventricular dilatation (left ventricular enddiastolic diameter $>75 \mathrm{~mm}$ or end-systolic diameter $>55 \mathrm{~mm})^{(7)}$ Several qualitative and quantitative measurements are used to grade severity of aortic regurgitation (Table 5). The reader is referred to the American Society of Echocardiography's Recommendations for evaluation of the severity of native valvular regurgitation with two-dimensional and Doppler echocardiography ${ }^{(42)}$ for complete details of the criteria including their utility, advantages, and limitations.

\section{Stress echocardiography in aortic regurgitation}

Aortic valve replacement is not indicated in patients with severe aortic regurgitation who are asymptomatic and who have normal left ventricular systolic function and no evidence of severe left ventricular dilatation. These patients can however develop latent left ventricular systolic dysfunction even in the absence of decreased systolic function at rest or significant ventricular dilatation. The response of left ventricular ejection fraction to exercise or dobutamine has been shown to be an important determinant of later development of overt left ventricular systolic dysfunction and a predictor of left ventricular functional recovery following aortic valve surgery. ${ }^{(110-112)}$ Therefore, stress echocardiography can be a useful adjunct in the serial evaluation of patients with asymptomatic severe aortic regurgitation. Wahi et al showed that contractile reserve on exercise echocardiography was a better predictor of subsequent left ventricular decompensation in patients treated medically and correlated better with resting left ventricular ejection fraction following aortic valve surgery. ${ }^{(110)}$ Impaired left ventricular contractile reserve assessed by low dose dobutamine echocardiography has also been shown to be a marker of irreversible left ventricular systolic dysfunction in patients undergoing aortic valve replacement for minimally symptomatic chronic severe aortic regurgitation. (III)

\begin{tabular}{|c|c|c|c|}
\hline & Mild & Moderate & Severe \\
\hline \multicolumn{4}{|l|}{ Structural parameters } \\
\hline LV size & Normal & Normal or dilated & Usually dilated \\
\hline Aortic leaflets & $\begin{array}{l}\text { Normal or } \\
\text { abnormal }\end{array}$ & $\begin{array}{l}\text { Normal or } \\
\text { abnormal }\end{array}$ & $\begin{array}{c}\text { Abnormal/prolapse } \\
\text { or wide coaptation } \\
\text { defect }\end{array}$ \\
\hline \multicolumn{4}{|l|}{ Doppler parameters } \\
\hline $\begin{array}{l}\text { Jet width in LVOT- } \\
\text { Colour Flow }\end{array}$ & Small in central jets & Intermediate & $\begin{array}{l}\text { Large in central } \\
\text { jets. Variable in } \\
\text { eccentric jets }\end{array}$ \\
\hline Jet density-CW & Incomplete of faint & Dense & Dense \\
\hline $\begin{array}{l}\text { Jet pressure half- } \\
\text { time, ms }\end{array}$ & Slow $>500$ & $500-200$ & $<200$ \\
\hline $\begin{array}{l}\text { Diastolic flow reversal } \\
\text { in descending aorta }\end{array}$ & $\begin{array}{c}\text { Brief, early } \\
\text { diastolic reversal }\end{array}$ & Intermediate & $\begin{array}{c}\text { Prominent } \\
\text { holodiastolic } \\
\text { reversal }\end{array}$ \\
\hline \multicolumn{4}{|l|}{ Quantitative parameters } \\
\hline VC width $(\mathrm{cm})$ & $<0.3$ & $0.3-0.60$ & $\geq 0.6$ \\
\hline $\begin{array}{l}\text { Jet width/LVOT } \\
\text { width (\%) }\end{array}$ & $<25$ & $25-64$ & $\geq 65$ \\
\hline $\begin{array}{l}\text { Jet CSAILVOT } \\
\text { CSA (\%) }\end{array}$ & $<5$ & $5-59$ & $\geq 60$ \\
\hline RVol (ml/beat) & $<30$ & $30-59$ & $\geq 60$ \\
\hline $\mathrm{RF}(\%)$ & $<30$ & $30-49$ & $\geq 50$ \\
\hline $\mathrm{ERO}(\mathrm{cm} 2)$ & $<0.10$ & $0.10-0.30$ & $\geq 0.30$ \\
\hline
\end{tabular}

$A R=$ aortic regurgitation. $C S A=$ cross sectional area. $C W=$ continuous wave doppler. $E R O A=$ effective regurgitant orifice area. $L V=$ left ventricle. $L V O T=$ left ventricular outflow tract. $P H T=$ pressure half-time. $P W=$ pulsed wave doppler. $R$ Vol = regurgitant volume. $R F=$ regurgitant fraction. $V C=$ vena contracta.

\section{CONCLUSION}

Stress echocardiography can be a very useful, integral part of the evaluation of patients with valvular heart disease. Its main applications are to evaluate the hemodynamic response to stress to help link exertional symptoms to underlying valve disease in patients who appear to have mild to moderate disease at rest, or, in the case of an "asymptomatic" patient with severe valve disease, to determine if limiting symptoms are indeed present. Stress echocardiography can unmask latent left ventricular systolic dysfunction in seemingly normal left ventricles at rest, determine whether there is contractile reserve in those with reduced left ventricular systolic function, and determine the presence and extent of viable hibernating myocardium in patients with depressed left ventricular systolic function, particularly in patients with ischaemic mitral regurgitation. An abnormal left ventricular response to exercise is an important predictor of subsequent systolic dysfunction and left ventricular recovery following valve surgery. 
There are however, several stress modalities and protocols in the literature pertaining to the utility of stress testing and stress echocardiography in patients with valvular heart disease. Additionally, patients studied are not uniform, and there have not been any randomised studies. As a result, Class I indications for stress testing in patients with valvular heart disease are few, limited mainly to mitral stenosis when there is discrepancy between resting echocardiographic findings and clinical findings ${ }^{(7)}$ or asymptomatic patients with severe aortic stenosis. ${ }^{\left({ }^{8}\right)}$ Emerging data supports the integration of stress testing and stress echocardiography into decision making for optimal management of patients with valvular heart diseases.

\section{REFERENCES}

I. Anonymous. Rheumatic fever and rheumatic heart disease. World Health Organisation Technical Report Series 2004;923: I - 122.

2. Nkomo VT, Gardin JM, Skelton TN, et al. Burden of valvular heart diseases: a population-based study. Lancet 2006;368: I005-II.

3. Nkomo VT. Epidemiology and prevention of valvular heart diseases and infective endocarditis in Africa. Heart 2007;93:1510-9.

4. Carapetis JR, McDonald M, Wilson NJ. Acute rheumatic fever. Lancet 2005: 366:155-68.

5. Marijon E, Ou P, Celermajer DS, et al. Prevalence of rheumatic heart disease detected by echocardiographic screening. N Engl J Med 2007;357:470-6.

6. lung B, Baron G, Butchart EG, et al. A prospective survey of patients with valvular heart disease in Europe: The Euro heart survey on valvular heart disease. Eur Heart J 2003;24:1231-43.

7. Bonow RO, Carabello BA, Chatterjee K, et al. ACC/AHA 2006 guidelines for the management of patients with valvular heart disease: a report of the American College of Cardiology/American Heart Association task force on practice guidelines (writing committee to revise the 1998 guidelines for the management of patients with valvular heart disease) developed in collaboration with the Society of Cardiovascular Anesthesiologists endorsed by the Society for Cardiovascular Angiography and Interventions and the Society of Thoracic Surgeons. J Am Coll Cardiol 2006;48:el - 148.

8. Vahanian A, Baumgartner $\mathrm{H}, \mathrm{Bax}$ J, et al. Guidelines on the management of valvular heart disease: The task force on the management of valvular heart disease of the European Society of Cardiology. Eur Heart J 2007;28:230-68.

9. Edwards JE, Rusted IE, Scheifley CH. Studies of the mitral valve. II. Certain anatomic features of the mitral valve and associated structures in mitral stenosis. Circulation 1956; | 4:398-406

10. Roberts WC, Perloff JK. Mitral valvular disease. A clinicopathologic survey of the conditions causing the mitral valve to function abnormally. Ann Intern Med 1972;77:939-75.

II. Braunwald E, Moscovitz HL, Amram SS, et al. The hemodynamics of the left side of the heart as studied by simultaneous left atrial, left ventricular, and aortic pressures; particular reference to mitral stenosis. Circulation 1955; 12:69-81.

12. Wood P. An appreciation of mitral stenosis: II. Investigations and results. Br Med J 1954;1:1 |1 3-24.

13. Gorlin R, Gorlin SG. Hydraulic formula for calculation of the area of the stenotic mitral valve, other cardiac valves, and central circulatory shunts. I. Am Heart J 1951;41:1-29.
14. Hugenholtz PG, Ryan T], Stein SW, et al. The spectrum of pure mitral stenosis. Hemodynamic studies in relation to clinical disability. Am J Cardiol 1962; 10:773-84

15. Henry WL, Griffith JM, Michaelis LL, et al. Measurement of mitral orifice area in patients with mitral valve disease by real-time, two-dimensional echocardiography. Circulation 1975;51:827-31.

16. Holen J, Aaslid R, Landmark K, et al. Determination of pressure gradient in mitral stenosis with a non-invasive ultrasound Doppler technique. Acta Med Scand 1976; 199:455-60.

17. Nichol PM, Gilbert BW, Kisslo JA. Two-dimensional echocardiographic assessment of mitral stenosis. Circulation 1977;55:120-8.

18. Hatle L, Brubakk A, Tromsdal A, et al. Non-invasive assessment of pressure drop in mitral stenosis by Doppler ultrasound. Br Heart J 1978;40:131-40.

19. Nishimura RA, Miller FA, Jr., Callahan MJ, et al. Doppler echocardiography: theory, instrumentation, technique, and application. Mayo Clin Proc 1985;60:32 I-43.

20. Schwammenthal E, Vered Z, Agranat $O$, et al. Impact of atrioventricular compliance on pulmonary artery pressure in mitral stenosis: an exercise echocardiographic study. Circulation 2000; 102:2378-84.

21. Flachskampf FA, Weyman AE, Gillam L, et al. Aortic regurgitation shortens Doppler pressure half-time in mitral stenosis: clinical evidence, in vitro simulation and theoretic analysis. J Am Coll Cardiol 1990; 16:396-404.

22. Kircher BJ, Himelman RB, Schiller NB. Non-invasive estimation of right atrial pressure from the inspiratory collapse of the inferior vena cava. Am J Cardiol 1990;66:493-6.

23. Decena BF, 3rd, Tischler MD. Stress echocardiography in valvular heart disease. Cardiol Clin 1999; 17:555-72, ix.

24. Nakhjavan FK, Katz MR, Shedrovilzky H, et al. Hemodynamic effects of exercise, catecholamine stimulation and tachycardia in mitral stenosis and sinus rhythm at comparable heart rates. Am J Cardiol 1969;23:659-66.

25. Sagar KB, Wann LS, Paulson WJ, et al. Role of exercise Doppler echocardiography in isolated mitral stenosis. Chest 1987;92:27-30.

26. Tunick PA, Freedberg RS, Gargiulo A, et al. Exercise Doppler echocardiography as an aid to clinical decision-making in mitral valve disease. J Am Soc Echocardiogr 1992;5:225-30.

27. Cheriex EC, Pieters FA, Janssen JH, et al. Value of exercise Doppler-echocardiography in patients with mitral stenosis. Int J Cardiol 1994;45:219-26.

28. Wu WC, Aziz GF, Sadaniantz A. The use of stress echocardiography in the assessment of mitral valvular disease. Echocardiography 2004;21:451-8.

29. Hecker SL, Zabalgoitia M, Ashline P, et al. Comparison of exercise and dobutamine stress echocardiography in assessing mitral stenosis. Am J Cardiol 1997;80:1374-7.

30. Mohan JC, Patel AR, Passey R, et al. Is the mitral valve area flow-dependent in mitral stenosis? A dobutamine stress echocardiographic study. J Am Coll Cardiol 2002;40: 1809-15.

31. Sicari R, Nihoyannopoulos P, Evangelista A, et al. Stress echocardiography expert consensus statement: European Association of Echocardiography (EAE) (a registered branch of the ESC). Eur J Echocardiogr 2008;9:415-37.

32. Aviles RJ, Nishimura RA, Pellikka PA, et al. Utility of stress Doppler echocardiography in patients undergoing percutaneous mitral balloon valvotomy. J Am Soc Echocardiogr 2001;14:676-81.

33. Pellikka PA, Nagueh SF, Elhendy AA, et al. American Society of Echocardiography recommendations for performance, interpretation, and application of stress echocardiography. J Am Soc Echocardiogr 2007;20:1021-41.

34. Reis G, Motta MS, Barbosa MM, et al. Dobutamine stress echocardiography for non-invasive assessment and risk stratification of patients with rheumatic mitral stenosis. J Am Coll Cardiol 2004:43:393-40I.

35. Braverman AC, Thomas JD, Lee RT. Doppler echocardiographic estimation of mitral valve area during changing hemodynamic conditions. Am J Cardiol |99|;68: |485-90. 


\section{REFERENCES}

36. Nakatani S, Masuyama T, Kodama K, et al. Value and limitations of Doppler echocardiography in the quantification of stenotic mitral valve area: comparison of the pressure half-time and the continuity equation methods. Circulation 1988;77:78-85

37. Karp K, Teien D, Bjerle P, et al Reassessment of valve area determinations in mitral stenosis by the pressure half-time method: impact of left ventricular stiffness and peak diastolic pressure difference. J Am Coll Cardiol 1989;1 3:594-9.

38. Loyd D, Ask P,Wranne B. Pressure half-time does not always predict mitral valve area correctly. J Am Soc Echocardiogr 1988; 1:313-21.

39. Firstenberg MS, Prior DL, Greenberg NL, et al. Effect of cardiac output on mitral valve area in patients with mitral stenosis: validation and pitfalls of the pressure half-time method. J Heart Valve Dis 200 I; 10:49-56.

40. Tamai J, Nagata S, Akaike $M$, et al. Improvement in mitral flow dynamics during exercise after percutaneous transvenous mitral commissurotomy. Non-invasive evaluation using continuous wave Doppler technique. Circulation 1990;81:46-51.

41. Essop MR, Wisenbaugh T, Sareli P. Evidence against a myocardial factor as the cause of left ventricular dilation in active rheumatic carditis. J Am Coll Cardiol 1993;22:826-9.

42. Zoghbi WA, Enriquez-Sarano M, Foster E, et al. Recommendations for evaluation of the severity of native valvular regurgitation with two-dimensional and Doppler echocardiography. J Am Soc Echocardiogr 2003; 16:777-802.

43. Enriquez-Sarano M, Avierinos JF, Messika-Zeitoun D, et al. Quantitative determinants of the outcome of asymptomatic mitral regurgitation. $N$ Engl J Med 2005;352:875-83.

44. Tischler MD, Battle RW, Saha M, et al. Observations suggesting a high incidence of exercise-induced severe mitral regurgitation in patients with mild rheumatic mitral valve disease at rest. J Am Coll Cardiol 1995;25: 128-33.

45. Lebrun F, Lancellotti P, Pierard LA. Quantitation of functional mitral regurgitation during bicycle exercise in patients with heart failure. J Am Coll Cardiol 2001;38:1685-92

46. Ling LH, Enriquez-Sarano M, Seward JB, et al. Clinical outcome of mitral regurgitation due to flail leaflet. N Engl J Med 1996;335:1417-23.

47. Ling LH, Enriquez-Sarano M, Seward JB, et al. Early surgery in patients with mitral regurgitation due to flail leaflets: a long-term outcome study. Circulation 1997;96:1819-25.

48. Suri RM, Schaff HV, Dearani JA, et al. Recurrent mitral regurgitation after repair: should the mitral valve be re-repaired? J Thorac Cardiovasc Surg 2006;132: 1390-7.

49. Suri RM, Schaff HV, Dearani JA, et al. Survival advantage and improved durability of mitral repair for leaflet prolapse subsets in the current era. Ann Thorac Surg 2006;82:819-26.

50. Enriquez-Sarano M, Akins CW, Vahanian A. Mitral regurgitation. Lancet 2009; 373: $1382-94$

5I. Messika-Zeitoun D, Johnson BD, Nkomo V, et al. Cardiopulmonary exercise testing determination of functional capacity in mitral regurgitation: physiologic and outcome implications. J Am Coll Cardiol 2006;47:2521-7.

52. Supino PG, Borer JS, Schuleri K, et al. Prognostic value of exercise tolerance testing in asymptomatic chronic non-ischaemic mitral regurgitation. Am J Cardiol 2007; 100:1274-81.

53. Haluska BA, Short L, Marwick TH. Relationship of ventricular longitudinal function to contractile reserve in patients with mitral regurgitation. Am Heart J 2003; | 46: 183-8.

54. Leung DY, Griffin BP, Stewart WJ, et al. Left ventricular function after valve repair for chronic mitral regurgitation: predictive value of preoperative assessment of contractile reserve by exercise echocardiography. J Am Coll Cardiol 1996; 28: | 198-205.
55. Lee R, Haluska B, Leung DY, et al. Functional and prognostic implications of left ventricular contractile reserve in patients with asymptomatic severe mitral regurgitation. Heart 2005;91:1407-12.

56. Lancellotti P, Cosyns B, Zacharakis D, et al. Importance of left ventricular longitudinal function and functional reserve in patients with degenerative mitral regurgitation: assessment by two-dimensional speckle tracking. J Am Soc Echocardiogr 2008;21:1331-6.

57. Yiu SF, Enriquez-Sarano M, Tribouilloy C, et al. Determinants of the degree of functional mitral regurgitation in patients with systolic left ventricular dysfunction: A quantitative clinical study. Circulation 2000; 102:1400-6.

58. Levine RA, Schwammenthal E. Ischaemic mitral regurgitation on the threshold of a solution: from paradoxes to unifying concepts. Circulation 2005; I I 2:745-58.

59. Bursi F, Enriquez-Sarano M, Nkomo VT, et al. Heart failure and death after myocardial infarction in the community: the emerging role of mitral regurgitation. Circulation 2005; 1 11:295-301.

60. Grigioni F, Enriquez-Sarano M, Zehr KJ, et al. Ischaemic mitral regurgitation: long-term outcome and prognostic implications with quantitative Doppler assessment. Circulation 200 I; 103:1759-64.

61. Enriquez-Sarano M, Schaff HV, Frye RL. Mitral regurgitation: what causes the leakage is fundamental to the outcome of valve repair. Circulation 2003;108: 253-6.

62. Magne J, Girerd N, Senechal M, et al. Mitral repair versus replacement for ischaemic mitral regurgitation: comparison of short-term and long-term survival. Circulation 2009; 120:S104-II.

63. McGee EC, Gillinov AM, Blackstone EH, et al. Recurrent mitral regurgitation after annuloplasty for functional ischaemic mitral regurgitation. J Thorac Cardiovasc Surg 2004; 128:916-24.

64. Wu AH, Aaronson KD, Bolling SF, et al. Impact of mitral valve annuloplasty on mortality risk in patients with mitral regurgitation and left ventricular systolic dysfunction. J Am Coll Cardiol 2005;45:38I-7.

65. Mihaljevic T, Lam BK, Rajeswaran J, et al. Impact of mitral valve annuloplasty combined with revascularisation in patients with functional ischaemic mitral regurgitation. J Am Coll Cardiol 2007;49:2191-20I.

66. Rukosujew A, Klotz S, Welp H, et al. Surgery of secondary mitral insufficiency in patients with impaired left ventricular function. J Cardiothorac Surg 2009;4:36.

67. Lancellotti P, Lebrun F, Pierard LA. Determinants of exercise-induced changes in mitral regurgitation in patients with coronary artery disease and left ventricular dysfunction. J Am Coll Cardiol 2003;42:1921-8.

68. Lancellotti P, Troisfontaines P, Toussaint AC, et al. Prognostic importance of exercise-induced changes in mitral regurgitation in patients with chronic ischaemic left ventricular dysfunction. Circulation 2003; 108:17/3-7.

69. Pierard LA, Lancellotti $P$. The role of ischaemic mitral regurgitation in the pathogenesis of acute pulmonary oedema. N Engl J Med 2004;35 I: 1627-34.

70. Fehrenbacher G, Schmidt DH, Bommer WJ. Evaluation of transient mitral regurgitation in coronary artery disease. Am J Cardiol 1991;68:868-73.

71. Peteiro J, Freire E, Montserrat $L$, et al. The effect of exercise on ischaemic mitral regurgitation. Chest 1998; I 4:1075-82.

72. Peteiro J, Monserrat L, Bouzas B, et al. Effect of left ventricular global systolic function, mitral regurgitation, and left ventricular inflow pattern on exercise echocardiography results. Echocardiography 2002; 19:1 $15-23$.

73. Picano E, Pibarot P, Lancellotti $P$, et al. The emerging role of exercise testing and stress echocardiography in valvular heart disease. J Am Coll Cardiol 2009;54: 225I-60.

74. Sicari R, Picano E, Cortigiani L, et al. Prognostic value of myocardial viability recognised by low-dose dobutamine echocardiography in chronic ischaemic left ventricular dysfunction. Am J Cardiol 2003;92:1263-6. 
75. Rizzello V, Poldermans D, Boersma E, et al. Opposite patterns of left ventricular remodeling after coronary revascularisation in patients with ischaemic cardiomyopathy: role of myocardial viability. Circulation 2004; 1 1 0:2383-8.

76. Schinkel AF, Bax JJ, Poldermans D, et al. Hibernating myocardium: diagnosis and patient outcomes. Curr Probl Cardiol 2007;32:375-4I0.

77. Camici PG, Prasad SK, Rimoldi OE. Stunning, hibernation, and assessment of myocardial viability. Circulation 2008; 1 17:103-14.

78. He S, Fontaine AA, Schwammenthal E, et al. Integrated mechanism for functional mitral regurgitation: leaflet restriction versus coapting force: in vitro studies. Circulation 1997;96: 1826-34.

79. Trichon BH, Felker GM, Shaw LK, et al. Relation of frequency and severity of mitral regurgitation to survival among patients with left ventricular systolic dysfunction and heart failure. Am J Cardiol 2003;91:538-43.

80. Yamano T, Nakatani S, Kanzaki H, et al. Exercise-induced changes of functional mitral regurgitation in asymptomatic or mildly symptomatic patients with idiopathic dilated cardiomyopathy. Am J Cardiol 2008; 102:48। -5.

81. Keren G, Katz S, Strom J, et al. Dynamic mitral regurgitation. An important determinant of the hemodynamic response to load alterations and inotropic therapy in severe heart failure. Circulation 1989;80:306-13.

82. Sonoda M, Takenaka K, Sakamoto T, et al. Effects of dobutamine infusion on mitral regurgitation. Echocardiography 1998; 15:13-20.

83. Commerford PJ, Curcio A, Albanese M, et al. Aortic valve replacement in the elderly. S Afr Med J 1981;59:975-6.

84. Otto CM, Kuusisto J, Reichenbach DD, et al. Characterisation of the early lesion of "degenerative" valvular aortic stenosis. Histological and immunohistochemical studies. Circulation 1994;90:844-53.

85. Olsson M, Dalsgaard C], Haegerstrand A, et al. Accumulation of T-lymphocytes and expression of interleukin-2 receptors in non-rheumatic stenotic aortic valves. J Am Coll Cardiol 1994;23: I 162-70.

86. Mohler ER, Sheridan MJ, Nichols R, et al. Development and progression of aortic valve stenosis: atherosclerosis risk factors - a causal relationship? A clinical morphologic study. Clin Cardiol 1991;14:995-9.

87. Gotoh T, Kuroda T, Yamasawa M, et al. Correlation between lipoprotein(a) and aortic valve sclerosis assessed by echocardiography (the JMS Cardiac Echo and Cohort Study). Am J Cardiol 1995;76:928-32.

88. Ross J, Jr., Braunwald E. Aortic stenosis. Circulation 1968;38:61-7.

89. Lund $\mathrm{O}$, Nielsen TT, Emmertsen K, et al. Mortality and worsening of prognostic profile during waiting time for valve replacement in aortic stenosis. Thorac Cardiovasc Surg 1996;44:289-95.

90. Otto CM. Valvular aortic stenosis: disease severity and timing of intervention. J Am Coll Cardiol 2006;47:2141-5I.

91. Dal-Bianco JP, Khandheria BK, Mookadam F, et al. Management of asymptomatic severe aortic stenosis. J Am Coll Cardiol 2008;52:1279-92.

92. Pellikka PA, Sarano ME, Nishimura RA, et al. Outcome of 622 adults with asymptomatic, hemodynamically significant aortic stenosis during prolonged follow-up. Circulation 2005; 1 11:3290-5.

93. Coglianese EE, Davidoff R. Predicting outcome in patients with asymptomatic aortic stenosis. Circulation 2009;120:9-1।.

94. Rosenhek R, Binder T, Porenta G, et al. Predictors of outcome in severe, asymptomatic aortic stenosis. N Engl J Med 2000;343:6I I-7.

95. Otto CM, Burwash IG, Legget ME, et al. Prospective study of asymptomatic valvular aortic stenosis. Clinical, echocardiographic, and exercise predictors of outcome. Circulation 1997;95:2262-70.

96. Clyne CA, Arrighi JA, Maron BJ, et al. Systemic and left ventricular responses to exercise stress in asymptomatic patients with valvular aortic stenosis. Am J Cardiol 1991;68:1469-76.
97. Otto CM, Pearlman AS, Kraft CD, et al. Physiologic changes with maximal exercise in asymptomatic valvular aortic stenosis assessed by Doppler echocardiography. J Am Coll Cardiol 1992;20:1 160-7.

98. Amato MC, Moffa PJ, Werner KE, et al. Treatment decision in asymptomatic aortic valve stenosis: role of exercise testing. Heart 200 I;86:38I-6.

99. Alborino D, Hoffmann JL, Fournet PC, et al. Value of exercise testing to evaluate the indication for surgery in asymptomatic patients with valvular aortic stenosis. J Heart Valve Dis 2002; 1 1:204-9.

100. Das P, Rimington H, Chambers J. Exercise testing to stratify risk in aortic stenosis. Eur Heart J 2005;26: I 309- I3.

10I. Lancellotti P, Lebois F, Simon M, et al. Prognostic importance of quantitative exercise Doppler echocardiography in asymptomatic valvular aortic stenosis. Circulation 2005; 1 1 2:1377-82.

102. Burwash IG. Low-flow, low-gradient aortic stenosis: from evaluation to treatment. Curr Opin Cardiol 2007;22:84-91.

103. Agricola E, Oppizzi M, Pisani M, et al. Stress echocardiography in heart failure. Cardiovasc Ultrasound 2004;2:1 I.

104. Monin JL, Monchi M, Gest V, et al. Aortic stenosis with severe left ventricular dysfunction and low transvalvular pressure gradients: risk stratification by lowdose dobutamine echocardiography. J Am Coll Cardiol 200 1;37:2101-7.

105. Nishimura RA, Grantham JA, Connolly HM, et al. Low-output, low-gradient aortic stenosis in patients with depressed left ventricular systolic function: the clinical utility of the dobutamine challenge in the catheterisation laboratory. Circulation 2002; 106:809-13.

106. Monin JL, Quere JP, Monchi M, et al. Low-gradient aortic stenosis: operative risk stratification and predictors for long-term outcome: a multi-centre study using dobutamine stress hemodynamics. Circulation 2003; 108:319-24.

107. Tribouilloy C, Levy F, Rusinaru D, et al. Outcome after aortic valve replacement for low-flow/low-gradient aortic stenosis without contractile reserve on dobutamine stress echocardiography. J Am Coll Cardiol 2009:53:1865-73.

108. Halkos ME, Chen EP, Sarin EL, et al. Aortic valve replacement for aortic stenosis in patients with left ventricular dysfunction. Ann Thorac Surg 2009;88:746-5।.

109. Mautner GC, Roberts WC. Reported frequency of coronary arterial narrowing by angiogram in patients with valvular aortic stenosis. Am J Cardiol 1992;70: 539-40.

1 10. Wahi S, Haluska B, Pasquet A, et al. Exercise echocardiography predicts development of left ventricular dysfunction in medically and surgically treated patients with asymptomatic severe aortic regurgitation. Heart 2000;84:606-I4.

I I I. Tam JW, Antecol D, Kim HH, et al. Low dose dobutamine echocardiography in the assessment of contractile reserve to predict the outcome of valve replacement for chronic aortic regurgitation. Can J Cardiol 1999;1 1:73-9.

I 1 2. Espinola-Zavaleta N, Gomez-Nunez N, Chavez PY, et al. Evaluation of the response to pharmacological stress in chronic aortic regurgitation. Echocardiography 2001; | 8:49|-6. 